\title{
Enhanced Oil Recovery
}

and $\mathrm{CO}_{2}$ Storage Potential

Outside North America:

An Economic Assessment

Colin Ward, Wolfgang Heidug and Nils-Henrik Bjurstrøm 


\section{About KAPSARC}

The King Abdullah Petroleum Studies and Research Center (KAPSARC) is a non-profit global institution dedicated to independent research into energy economics, policy, technology and the environment, across all types of energy. KAPSARC's mandate is to advance the understanding of energy challenges and opportunities facing the world today and tomorrow, through unbiased, independent, and high-caliber research for the benefit of society. KAPSARC is located in Riyadh, Saudi Arabia.

\section{Legal Notice}

(C) Copyright 2018 King Abdullah Petroleum Studies and Research Center (KAPSARC). No portion of this document may be reproduced or utilized without the proper attribution to KAPSARC. 


\section{Key Points}

toring carbon dioxide $\left(\mathrm{CO}_{2}\right)$ in oil reservoirs as part of $\mathrm{CO}_{2}$-based enhanced oil recovery $\left(\mathrm{CO}_{2}\right.$-EOR) can be a cost-effective solution to reduce emissions into the atmosphere. In this paper, we analyze the economics of this option in order to estimate the amount of $\mathrm{CO}_{2}$ that could be profitably stored in different regions of the world. We consider situations in which the $\mathrm{CO}_{2}$-EOR operator either purchases the $\mathrm{CO}_{2}$ supplied or is paid for its storage. Building upon extensive datasets concerning the characteristics and location of oil reservoirs and emission sources, the paper focuses on opportunities outside North America. Using net present value (NPV) as an indicator for profitability, we conduct a break-even analysis to relate $\mathrm{CO}_{2}$ supply prices (positive or negative) to economically viable storage potential. The main insights of our findings include:

A total of about 40 gigatonnes of $\mathrm{CO}_{2}\left(\mathrm{GtCO}_{2}\right)$ from currently operating emission sources could be economically stored via $\mathrm{CO}_{2}$-EOR in our focus area. For reference, China currently emits about 10 $\mathrm{GtCO}_{2}$ per year.

Storage potential is dependent on $\mathrm{CO}_{2}$ prices, but only over a narrow range. At an oil price of $\$ 50$ per barrel (bbl), storage increases in proportion to the $\mathrm{CO}_{2}$ price - up until about $\$ 20$ per tonne of $\mathrm{CO}_{2}$ $\left(\mathrm{tCO}_{2}\right)$. Higher $\mathrm{CO}_{2}$ prices show diminishing returns for storage.

Approximately $6 \mathrm{GtCO}_{2}$, mainly in Russia, China, Indonesia and Oman, could be profitably stored at a negative or zero $\mathrm{CO}_{2}$ supply price, assuming an oil price of $\$ 50 / \mathrm{bbl}$. This corresponds to the situation where the operator receives no revenue for providing storage services.

Current fiscal regimes create a disincentive for storage. By taxing the $\mathrm{CO}_{2}$-EOR oil produced at the same rate as regular oil production, they reduce overall profitability of $\mathrm{CO}_{2}$-EOR projects and thus the economically available storage potential.

At present, there is a shortage of $\mathrm{CO}_{2}$ to satisfy potential demand created by $\mathrm{CO}_{2}$-EOR. If supply were logistically available, Saudi Arabia alone could technically store a total of about $25 \mathrm{GtCO}_{2}$ via $\mathrm{CO}_{2}$ EOR. For perspective, achieving the 2-Degree Scenario (2DS) of the International Energy Agency (IEA) requires storing $6.8 \mathrm{GtCO}_{2}$ per year by 2060 (IEA 2016). 


\section{Summary for Policymakers}

D espite significant interest in using carbon pricing to stimulate the application of $\mathrm{CO}_{2}$ -based enhanced oil recovery ( $\mathrm{CO}_{2}$-EOR) to cost-effectively reduce $\mathrm{CO}_{2}$ emissions, to date there is only limited information available on how carbon prices influence the economic viability of $\mathrm{CO}_{2}$ storage - and hence the total amount that could be economically stored. This study uses a bottom-up approach to shed light on the issue, combining data on oil fields and emission sources. As analyses of storage potential in North America are widely available, our study focuses on situations in other regions.

The methodology first involves screening to identify fields amenable for $\mathrm{CO}_{2}$-EOR. In a second step, we seek to connect emission sources with $\mathrm{CO}_{2}$ EOR opportunities, allowing for $\mathrm{CO}_{2}$ transportation distances of up to $500 \mathrm{~km}$. Additionally, we stipulate that sources must produce sufficient $\mathrm{CO}_{2}$ to meet peak demand of the $\mathrm{CO}_{2}$ flood.

In a final step, we estimate cost and revenue of a $\mathrm{CO}_{2}$-EOR project to assess the profitability and costeffectiveness of $\mathrm{CO}_{2}$-EOR in terms of net present value (NPV) for the operator, considering potential source and storage combinations. This calculation considers both situations in which the $\mathrm{CO}_{2}$-EOR operator pays for the $\mathrm{CO}_{2}$ used or is paid for the $\mathrm{CO}_{2}$ stored. The former arrangement reflects the present U.S. situation; the latter corresponds to a scenario in which carbon price policies are implemented to reduce $\mathrm{CO}_{2}$ emissions into the atmosphere.

Results of our analysis are most effectively assessed in terms of the combinations of $\mathrm{CO}_{2}$ value and amount of $\mathrm{CO}_{2}$ stored that deliver a break-even NPV (discounted at 10 percent) for specified oil prices. This criterion marks the onset of profitability and cost-effectiveness. For a fixed oil price, an increasingly positive $\mathrm{CO}_{2}$ supply price makes it profitable to store more $\mathrm{CO}_{2}$. However, after a certain point, this effect tapers off. For instance, outside of North America, at an oil price of $\$ 50$ per barrel (bbl), irrespective of the $\mathrm{CO}_{2}$ supply price, the potential for storage caps at 40 gigatonnes of $\mathrm{CO}_{2}\left(\mathrm{GtCO}_{2}\right)$ because all potential has been utilized. In this case, $40 \mathrm{GtCO}_{2}$ can be interpreted as the economic potential for $\mathrm{CO}_{2}$ storage by $\mathrm{CO}_{2}$-EOR.

Since the storage potential of $\mathrm{CO}_{2}$-EOR is sensitive to $\mathrm{CO}_{2}$ supply prices, minor policy adjustments can significantly impact the amount stored. We show that even at an oil price of $\$ 50 / \mathrm{bbl}$, a $\mathrm{CO}_{2}$ supply price of $\$ 20 / \mathrm{tCO}_{2}$ is sufficient to exhaust virtually all of the profitable storage capacity outside of North America. Moreover, for the same oil price, about 6.1 $\mathrm{GtCO}_{2}$ could be stored when the $\mathrm{CO}_{2}$ supply price is negative (i.e., the $\mathrm{CO}_{2}$-EOR operator pays to acquire $\mathrm{CO}_{2}$ ). The calculation assumes a net utilization of $0.6 \mathrm{tCO}_{2} / \mathrm{bbl}$, which exceeds the typical utilization factor of about $0.3 \mathrm{tCO}_{2} / \mathrm{bbl}$ for business-as-usual EOR operations. This increased $\mathrm{CO}_{2}$ utilization corresponds to a situation in which the operator increases $\mathrm{CO}_{2}$ consumption to produce more oil, leading to increased storage.

The economically viable storage potential of 40 $\mathrm{GtCO}_{2}$ is contingent upon cost-effective access to the $\mathrm{CO}_{2}$ supply from currently operating and emitting $\mathrm{CO}_{2}$ sources. If $\mathrm{CO}_{2}$ supply considerations are relaxed, the storage potential of $\mathrm{CO}_{2}$-EOR increases vastly. Under the relaxed conditions, the technical $\mathrm{CO}_{2}$-EOR storage potential in Saudi Arabia is about $25 \mathrm{GtCO}_{2}$, making it a top contender for this technology globally. In real-world circumstances, however, limited access to $\mathrm{CO}_{2}$ could become the main factor constraining the development of $\mathrm{CO}_{2}$ EOR projects. 


\section{Introduction}

$\mathrm{O}_{2}$-EOR (enhanced oil recovery using $\mathrm{CO}_{2}$ ) is a technology used by commercial oil producers: to extract additional oil from depleting fields, they inject $\mathrm{CO}_{2}$ and water directly into the reservoir. The injected $\mathrm{CO}_{2}$ chemically interacts with the in situ oil facilitating its flow to the production wells. Current commercial $\mathrm{CO}_{2}-$ EOR practices focus solely on optimizing oil production and maximizing profit; as the $\mathrm{CO}_{2}$ must be purchased, operators seek to control costs by injecting the minimum amount necessary. The benefit of $\mathrm{CO}_{2}$-EOR derives entirely from the additional revenue of enhanced oil extraction offsetting the cost of $\mathrm{CO}_{2}$.

From a climate change perspective, a growing concern for governments and industry, this technology is interesting because of its capability to provide long-term storage of the injected $\mathrm{CO}_{2}$. The amount of $\mathrm{CO}_{2}$ stored depends to a large degree on how a particular $\mathrm{CO}_{2}$-EOR project is operated and managed (Kovsek and Cakici 2005; Dai et al. 2013; Saini 2017). Taking account of the additional oil revenues, the net storage costs of $\mathrm{CO}_{2}$-EOR are substantially lower than those associated with other forms of carbon capture and storage (CCS). As a result of this cost advantage, $\mathrm{CO}_{2}$-EOR could be a stepping stone for the development of a large-scale $\mathrm{CO}_{2}$ storage infrastructure (ARI 2010).

The incentives for EOR-based storage could be strengthened by setting policy that puts a price on $\mathrm{CO}_{2}$ emissions into the atmosphere and/or offers payment for initiatives that store $\mathrm{CO}_{2}$ to avert such emissions. This creates potential for a $\mathrm{CO}_{2}$-EOR project to generate two revenue streams: one from the increased oil extraction and the other from storing $\mathrm{CO}_{2}$. Under such a policy regime, it becomes advantageous for operators to specifically design and manage $\mathrm{CO}_{2}$-EOR projects to optimize the revenues from both oil production and $\mathrm{CO}_{2}$ storage (van't Veld et al. 2012).
This analysis focuses on an EOR scenario that maximizes oil production and $\mathrm{CO}_{2}$ storage on the assumption that both goals are desirable and should be encouraged through public policy (IEA 2015). As assessments of the storage potential in North America are already available (NETL 2011; IEAGHG 2009), this paper contributes to the assessment of $\mathrm{CO}_{2}$-EOR potential by estimating the amount of $\mathrm{CO}_{2}$ that can be economically stored outside of North America. An emphasis on the sourcing of $\mathrm{CO}_{2}$ supply - or indeed matching supplies and sinks - is a key feature of our analysis. In this way, our analysis extends earlier work by the International Energy Agency (IEA 2015) on the technical potential of $\mathrm{CO}_{2}$-EOR, which did not cover economic aspects, and in particular the geographical matching of oil demand to $\mathrm{CO}_{2}$ supply.

\section{How $\mathrm{CO}_{2}$-EOR works}

EOR is usually implemented after primary (natural production) and secondary (involving pressure regulation) production methods have been exhausted in a given oil field, but may technically begin at any time. Enhanced production methods aim to 'unlock' some of the oil remaining in the reservoir by reducing its viscosity, thus making it easier to produce. These EOR methods typically rely on heat or a chemical process to increase the mobility of the oil in the reservoir.

In the case of $\mathrm{CO}_{2}-\mathrm{EOR}, \mathrm{CO}_{2}$ gas is injected into the reservoir and interacts with the oil in two ways depending on the temperature and pressure. If the pressure is high enough to reach the so-called minimum miscibility pressure (MMP), $\mathrm{CO}_{2}$ will dissolve into the oil and 'loosen' it from the formation. The $\mathrm{CO}_{2}$ gas injection phase is then often followed by a water injection phase, in which the water sweeps the newly freed oil toward the production wells. Gas and water injection phases 
then continue in a process called water alternating with gas (WAG) until the oil production falls below economically viable levels. Should the reservoir pressure stay below the MMP after injection, the injected $\mathrm{CO}_{2}$ will not mix with the oil but push it toward the production well in a piston-like manner in what is called an immiscible flood.

The $\mathrm{CO}_{2}$ dissolved in the produced oil is then recovered and recycled for re-injection. This means that virtually all $\mathrm{CO}_{2}$ delivered and injected over the lifetime of the project should remain in the reservoir once production has halted, apart from minor leakage through fugitive emissions. To be of benefit from a climate policy perspective, the $\mathrm{CO}_{2}$ stored as part of $\mathrm{CO}_{2}$-EOR needs to remain effectively contained in the subsurface. To ensure this, the operator must undertake appropriate measurement and verification activities, as specified in relevant regulatory guidelines (IEAGHG 2016). As most currently operating $\mathrm{CO}_{2}$ EOR projects do not carry out these monitoring activities, there is no certainty regarding the amount of $\mathrm{CO}_{2}$ that is effectively stored.

Current business-as-usual practices focus on optimizing oil extraction with the minimum amount of $\mathrm{CO}_{2}$. These practices typically use around 0.3
$\mathrm{tCO}_{2} / \mathrm{bbl}$ to produce an additional 6.5 percent of the original oil in place (OOIP). However, a more innovative approach that seeks to optimize $\mathrm{CO}_{2}$ utilization and oil production may yield significantly better outcomes. With a miscible $\mathrm{CO}_{2}$ flood, the IEA (2015) suggests a storagefocused $\mathrm{CO}_{2}$ utilization of $0.6 \mathrm{tCO}_{2} / \mathrm{bbl}$, allowing incremental recovery of 13 percent of the OOIP. The corresponding numbers for EOR operations using immiscible flooding are $0.65 \mathrm{tCO}_{2} / \mathrm{bbl}$ with an incremental recovery of 4 percent of the OOIP. Immiscible flooding is typically less effective for enhancing oil production than miscible flooding (Jarell et al. 2002).

A simplified picture of a $\mathrm{CO}_{2}$-EOR project is shown in Figure 1. After arriving at the project site, the $\mathrm{CO}_{2}$ enters the surface facilities and is compressed for injection into the reservoir through an injection well. In the reservoir, the $\mathrm{CO}_{2}$ either dissolves into the oil or physically pushes the oil toward a production well where a slurry of oil, water and gas then exits the reservoir. The recycling facilities separate the $\mathrm{CO}_{2}$ from the oil (a simple settling drum is often sufficient, with gas exiting the top and liquids exiting the bottom). The recovered $\mathrm{CO}_{2}$ is reinjected while the oil is processed and exported through the existing production facilities. 


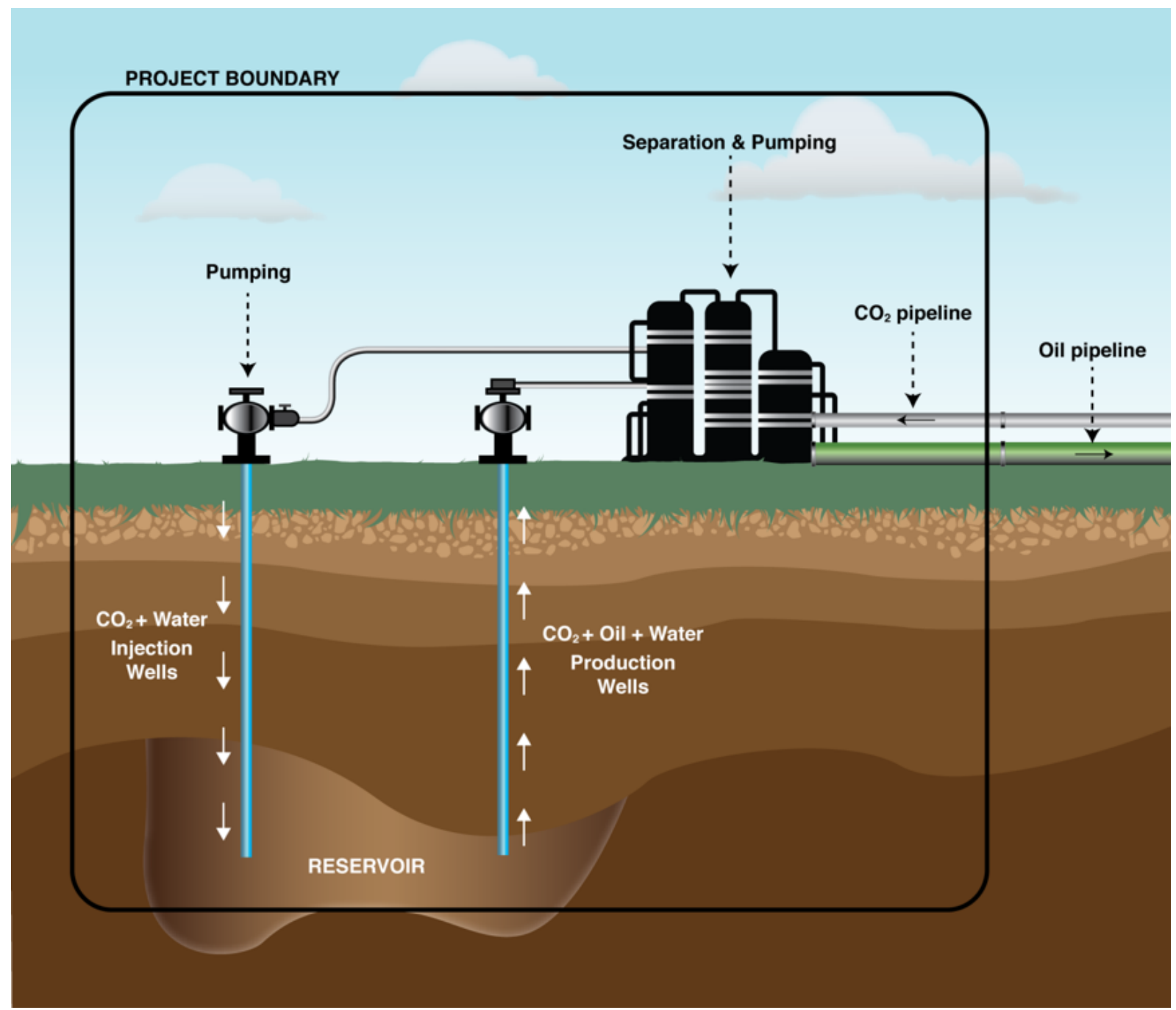

Figure 1. Main elements of $\mathrm{CO}_{2}$-EOR facilities and boundaries for economic analysis.

Source: KAPSARC. 


\section{Screening Methodology to Select Candidate Fields for $\mathrm{CO}_{2}$-EOR}

o identify fields with economic potential (rather than straight technical potential) for $\mathrm{CO}_{2}-$ EOR, we carried out a three-step process of mining databases and available information. The first step involved setting specific criteria against the total population of available fields. We then identified existing sources of $\mathrm{CO}_{2}$ supply and finally assessed the geographical 'match' of demand and supply.

\section{Assessing available fields for $\mathrm{CO}_{2}$-EOR}

A first step to estimate global $\mathrm{CO}_{2}$ storage potential under an approach that seeks to optimize EOR and $\mathrm{CO}_{2}$ storage (hereafter referred to as storage-focused), is to assess available fields. For this, we used UCube, the global field-level database compiled by Rystad Energy, which has information on reservoirs and the production status for approximately 35,000 oil and gas fields. To select $\mathrm{CO}_{2}$-EOR candidate fields, we applied the following criteria against the data in UCube:

Field status: only on-shore oil fields that are currently producing, abandoned or assumed to start production before 2025 are considered.

Flood type: the type may be either miscible or immiscible, depending on the MMP, which was estimated based on the oil mass density (API) and reservoir temperature for each reservoir examined. Broadly, if the MMP is greater than the reservoir pressure (Pr), then the $\mathrm{CO}_{2}$ is not miscible (dissolvable) into the oil, indicating an immiscible flood.

Gas/oil ratio (GOR): a large volume of existing gas in a reservoir undermines the effectiveness of $\mathrm{CO}_{2}$-EOR operations for several reasons. More gas indicates a saturated oil with dissolved gases already present, reducing the ability of the $\mathrm{CO}_{2}$ to interact directly with the crude. The compressibility of the gas cap also makes it difficult to push the oil to the production wells. For this reason, reservoirs with little or no gas cap were selected, as determined by the GOR. Specifically, we required the GOR to be less than 25 percent.

Breakthrough potential: the fluids injected into a reservoir, whether gas or liquid, tend to be much more mobile than the in-situ crude. Breakthrough occurs when these injection fluids enter the production stream. A low resistance path for the injection fluids between injection and production wells can significantly reduce their ability to drive the oil, as they bypass most of the reserves. The mobility of the oil, a primary determinant of when breakthrough will occur, is correlated to its viscosity. Fields with very low viscosity ( $<10 \mathrm{cP})$ have been excluded from the sample.

Additional factors: some characteristics warrant omitting fields from the candidate list. Offshore reservoirs were excluded entirely, as they are a tiny fraction of the total $\mathrm{CO}_{2}$-EOR potential outside of North America, and are technically very challenging to develop. Additionally, we excluded existing onshore projects that have already produced more than 80 percent of their reserves (defined as being well into tertiary production). As this is close to the highest technical recovery factor possible for most EOR methods, it leaves little oil for the EOR process to recover. Similarly, onshore reservoirs with less than 10 million barrels (MMbbl) of incremental production remaining were determined to be uneconomic as stand-alone projects. Finally, smaller fields (with a minimum 0.7 million incremental barrels available) were considered only if located within $20 \mathrm{~km}$ of a stand-alone project and able to operate as a tie-in. 
This initial filtering process identified a population of reservoirs that show strong potential for $\mathrm{CO}_{2}$ storage if enough supply is present. The next step was to assess the $\mathrm{CO}_{2}$ supply available for these fields.

\section{Locating $\mathrm{CO}_{2}$ supply}

To develop a technically feasible $\mathrm{CO}_{2}$-EOR project, a producer must secure sufficient local supply of $\mathrm{CO}_{2}$. To find potential $\mathrm{CO}_{2}$ sources for each candidate $\mathrm{CO}_{2}$-EOR project, we accessed the European Emission Database for Global Atmospheric Research (EDGAR 2017), which tracks historical $\mathrm{CO}_{2}$ emissions from stationary sources worldwide and categorizes them according to the type of source (Figure 2).

While EDGAR delivers high-resolution information, its handling is computationally intensive. To make the process of source-sink matching more manageable, we decreased the data resolution to a $1 \times 1$-degree grid (corresponding to a cell size of approximately $111 \mathrm{~km} \times 111 \mathrm{~km}$ ), covering the entire globe (Figure 3). The center of each pixel was used to determine distances between $\mathrm{CO}_{2}$ supplies and potential $\mathrm{CO}_{2}$ EOR projects. To ensure sufficient $\mathrm{CO}_{2}$ supply, we stipulated that supply must meet peak demand of the $\mathrm{CO}_{2}$-EOR project.

After determining the sources and $\mathrm{CO}_{2}$ demanded for each potential $\mathrm{CO}_{2}$-EOR candidate, viable supply/ demand pairs were identified by selecting the closest source with sufficient supply for each project. $\mathrm{CO}_{2}$ supply and demand were also considered from the perspective that supply typically remains constant over several years while $\mathrm{CO}_{2}$ demand drops following peak oil production: thus, a single $\mathrm{CO}_{2}$ source could consecutively supply multiple EOR projects. Our analysis assumes that the most economically attractive source-sink combination is developed first until demand drops; then the next project may proceed. Based on existing projects and economic considerations, we set $500 \mathrm{~km}$ as the maximum distance for $\mathrm{CO}_{2}$ delivery from source to sink. Over this distance, pipeline is the preferred way of transporting the high volumes of $\mathrm{CO}_{2}$ required for EOR projects. Existing $\mathrm{CO}_{2}$-EOR projects suggest that the pipeline must be sized to deliver, in a single year, a peak $\mathrm{CO}_{2}$ supply of roughly 15 percent of the lifetime $\mathrm{CO}_{2}$ demand.

A total of 2,355 $\mathrm{CO}_{2}$-EOR opportunities in 30 countries were identified using the methodology described.

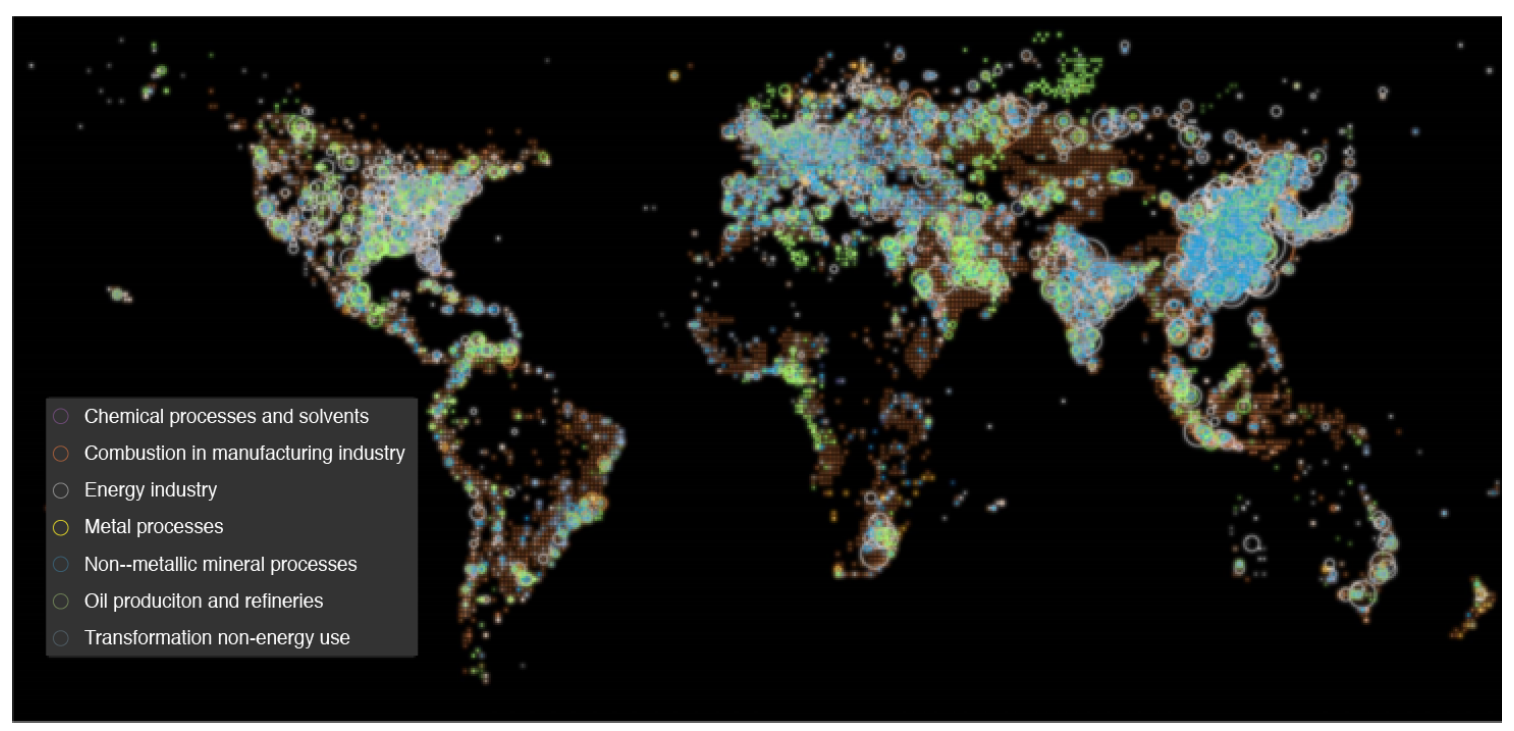

Figure 2. EDGAR database results for stationary emissions.

Source: EDGAR. 


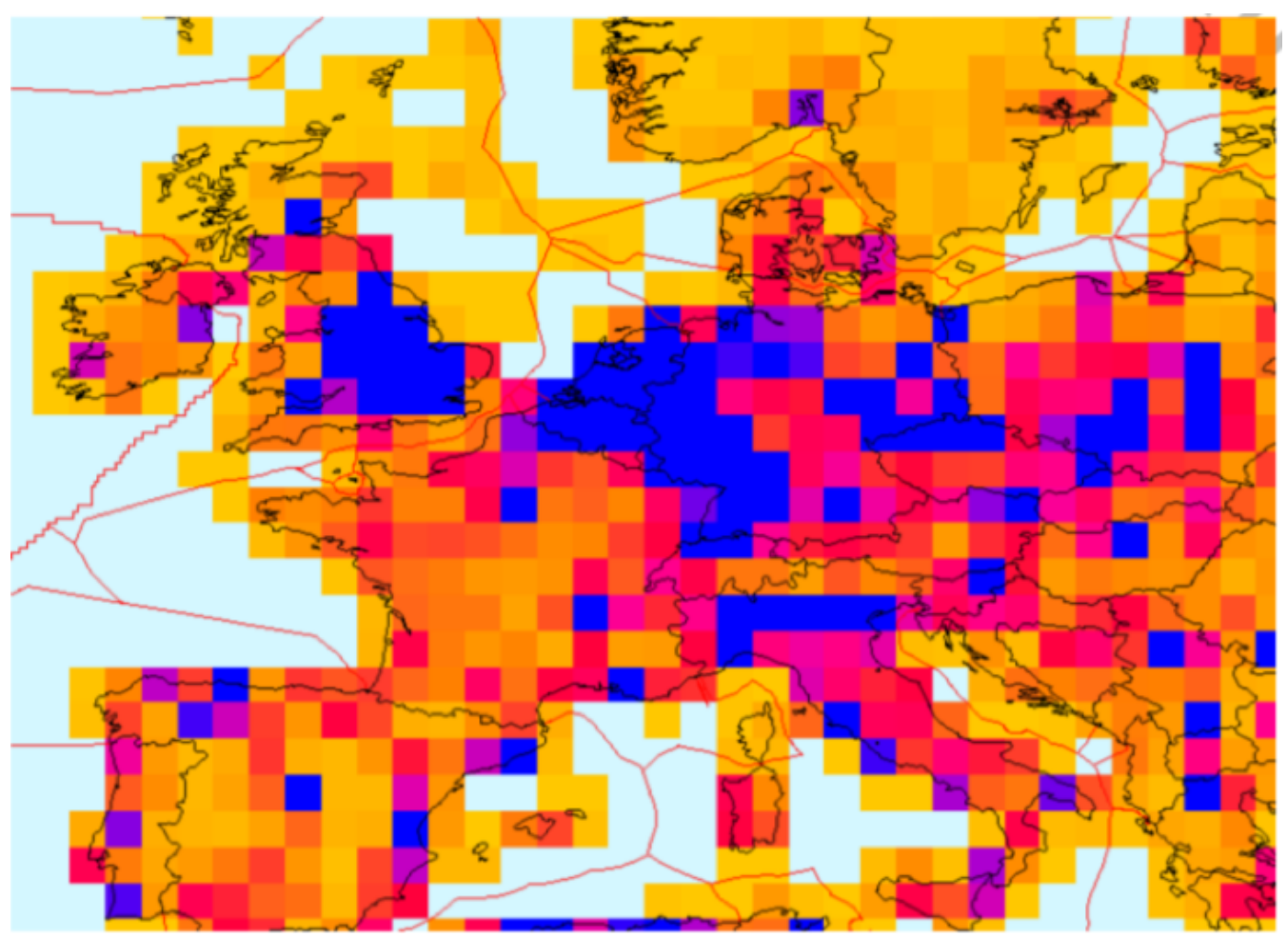

Figure 3. EDGAR data for Europe converted into $1 \times 1$-degree grid of stationary emissions.

Note: Darker colors indicate higher concentrations of emissions.

Source: EDGAR.

\section{Geographic distribution of $\mathrm{CO}_{2}$ sinks and sources}

Figure 4 shows the countries outside of North America with the largest $\mathrm{CO}_{2}$ storage potential with sufficient supply. Russia tops the list in terms of currently available $\mathrm{CO}_{2}$-EOR opportunities (11.900 $\mathrm{GtCO}_{2}$ ), followed by China (5.381 $\mathrm{GtCO}_{2}$ ) and Iran $\left(2.932 \mathrm{GtCO}_{2}\right)$. For comparison, the chart also indicates technical storage potential, i.e., unconstrained by the availability of $\mathrm{CO}_{2}$ from anthropogenic sources. The orange bars in the figure show that EOR-based storage opportunities vastly exceed the amount of $\mathrm{CO}_{2}$ currently available (blue bars) from local sources, particularly in Russia, Saudi Arabia and Iraq.

Another interesting finding is that most of the candidate projects can be arranged in clusters. In fact, 1,990 of the 2,355 projects considered can be grouped into 32 clusters (Figure 5). Often, these clusters comprise several reservoirs within the same geological formations, with a $\mathrm{CO}_{2}$ source in the vicinity. Clusters allow for a stable $\mathrm{CO}_{2}$ supply and shared $\mathrm{CO}_{2}$ transportation infrastructure, which could translate into reducing overall capital and operational expenses (CAPEX and OPEX).

About $40 \mathrm{GtCO}_{2}$ from currently operating stationary sources in our focus area could be stored through $\mathrm{CO}_{2}$-EOR, with an approximate incremental production of 66 billion barrels of oil. Validating the prior filtering methodology, almost all of the potential opportunities are onshore, with offshore storage representing a mere $2 \mathrm{GtCO}_{2}$. Miscible flooding holds the majority (35 Gt) of the onshore storage potential, with most of it coming from currently producing fields in the Middle East, China and Russia. 


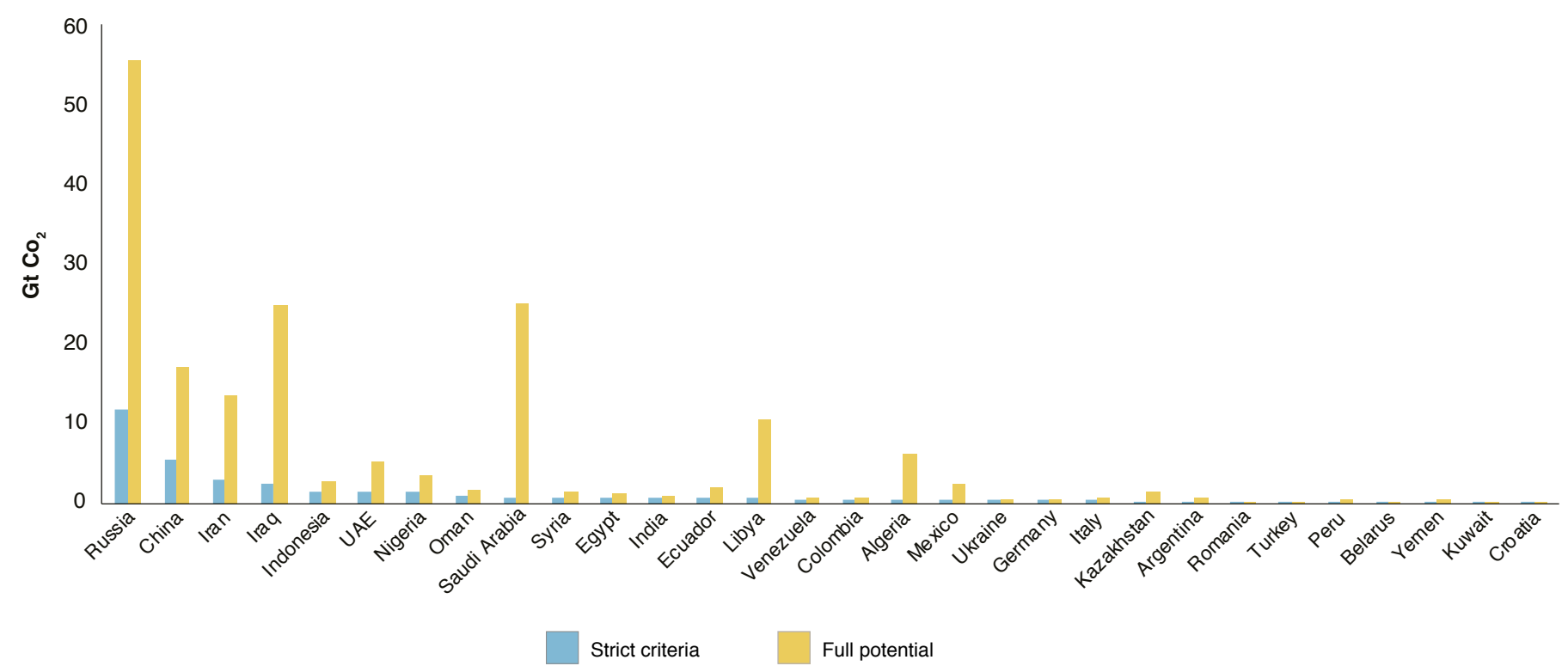

Onshore potential $\mathrm{CO}_{2}$ storage

Figure 4. $\mathrm{CO}_{2}$-EOR storage potential with strict criteria (sufficient $\mathrm{CO}_{2}$ supply) versus technical potential. Source: KAPSARC.

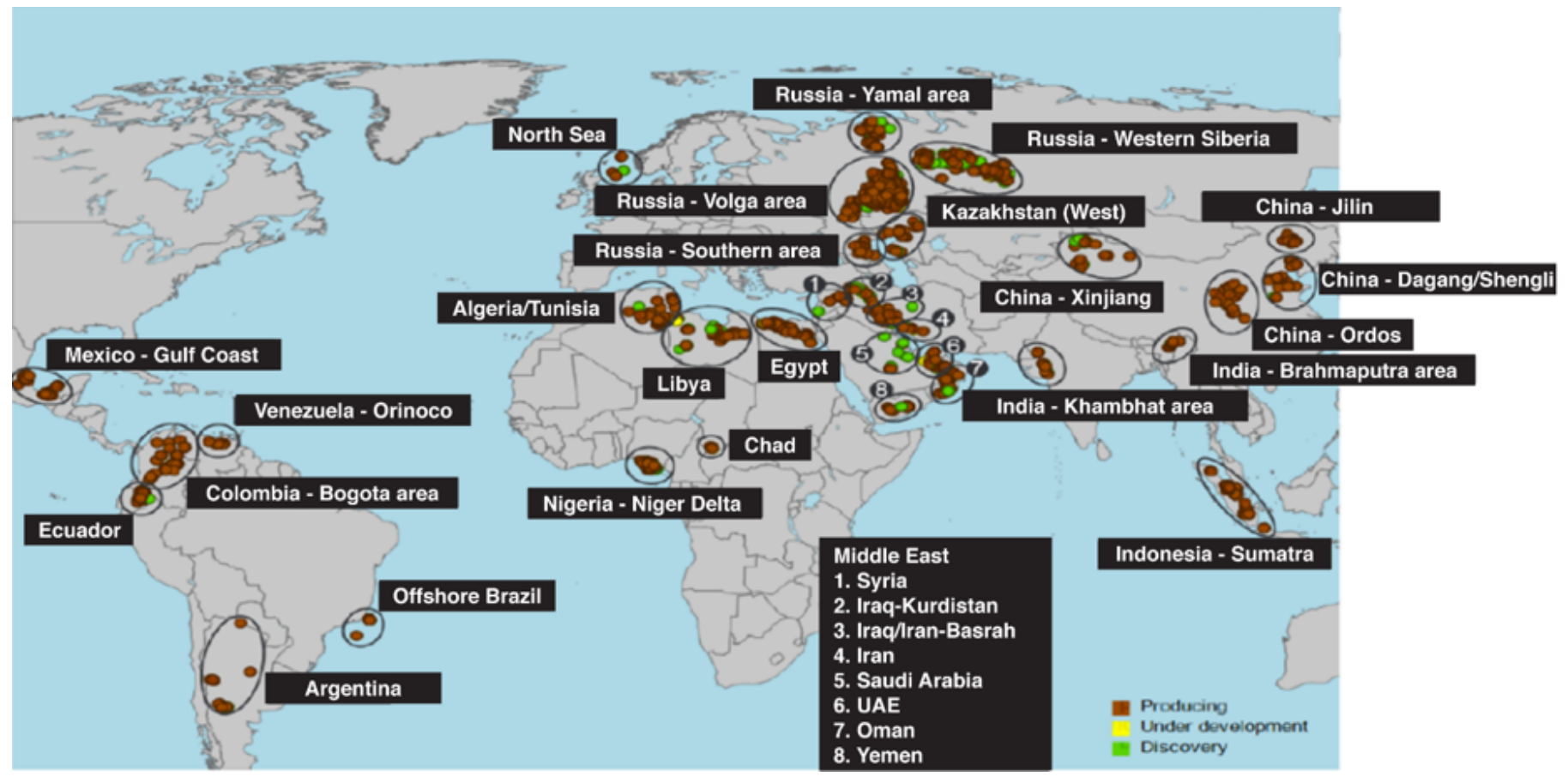

Figure 5. Potential clusters for $\mathrm{CO}_{2}$-EOR development outside of North America.

Source: Rystad. 


\section{Economics}

U nless a reasonable return on investment (ROI) can be assured, no oil producer will ever invest in a $\mathrm{CO}_{2}$-EOR project. To assess economic fitness of a project, CAPEX and OPEX costs, along with potential revenues, must be determined.

\section{Costing $\mathrm{CO}_{2}$-EOR projects}

The total amount of $\mathrm{CO}_{2}$ that is stored via commercial $\mathrm{CO}_{2}$-EOR projects crucially depends on individual project profitability. We thus sought to estimate the profitablilty of the $2,355 \mathrm{CO}_{2}$-EOR opportunities identified through our methodology. Performing a detailed cash flow analysis for this many projects was impractical, not only because of the large number of fields but also due to the lack of essential data required to quantify oil production and $\mathrm{CO}_{2}$ storage curves for each reservoir. These data are commercially sensitive, and generally not available to the public.

To work around this challenge, we assumed that all fields exhibit similar incremental oil production and $\mathrm{CO}_{2}$ storage performance. We determined some standard production and injection curves, and scaled them (both annually and temporally) to match the size of the reservoirs. Given the constraints on data mentioned above, an assumption of this type might be considered 'courageous' but is necessary for estimating the economics of $\mathrm{CO}_{2}$-EOR.

Costing of $\mathrm{CO}_{2}$-EOR projects depends on the components included in the calculation (Figure 1). For this analysis, which examines only the behavior of the oil producer in response to the experienced $\mathrm{CO}_{2}$ supply price, we consider that all cost items pertaining to $\mathrm{CO}_{2}$ delivery are outside our scope. The challenges of capture and transport are deliberately avoided, and assumed to be included in the supply price incurred by the EOR operator.
Similarly, the emission price of $\mathrm{CO}_{2}$ as set by climate policy is exogenous to these considerations.

Costs and revenues for a $\mathrm{CO}_{2}$-EOR project are relatively simple. The main CAPEX components are related to the drilling and completion of injection and production wells, and the installation of recycling facilities. In the operation phase, OPEX comprises the purchase of $\mathrm{CO}_{2}$, worker salaries and the cost of energy. When the project reaches the end of its lifetime, decommissioning (DECOM) costs are incurred for shutting down operations and making the site safe (details of the cost estimation process are given in Appendix A). For revenues, oil production and potential $\mathrm{CO}_{2}$ storage income are considered as the only sources.

Other factors that significantly affect the economics of $\mathrm{CO}_{2}$-EOR projects are the percentage of revenue collected by governments in the form of taxes, royalty payments and other charges. To evaluate the impact of the government's take on NPV in each country, we used the fiscal information collected in the proprietary IHS Markit Vantage database. These data cover details of the fiscal terms between governments and oil companies, together with the type of contractual arrangement (e.g., concessions or production sharing agreements). To keep the calculation simple and avoid the need to consider carryforwards, we assumed that EOR projects are not fiscally ring-fenced. This enables operators to consolidate all cash flows over a portfolio of projects, thereby gaining the full value of any tax benefits in the year in which they occur.

\section{Storage potential as a function of breakeven $\mathrm{CO}_{2}$ price}

The net present value (NPV) of a project is a financial indicator that compares expenditures and revenues occurring over the lifetime of a project 
in terms of today's money. It is calculated by discounting future cash flows by a set rate for each year in which they occur. The discount rate is a key assumption for this calculation, and is crucially dependent on the perceived risk of the project. High risk projects command a high discount rate. The economics of $\mathrm{CO}_{2}$-EOR is particularly sensitive to the choice of the discount rate because of the large CAPEX expenditure occurring early in the life of a project. The OPEX, as well as net revenues from oil production and potentially from $\mathrm{CO}_{2}$ storage, will materialize over many years and are reduced significantly through discounting, especially at higher rates. For the purposes of this analysis, we have selected a flat 10 percent discount rate.

To identify the price of $\mathrm{CO}_{2}$ at which EOR becomes an economically viable option for storage, the NPV breakeven point is the appropriate indicator. At this price the project's NPV is zero and the operator neither earns nor loses money.

Figure 6 shows the estimated break-even $\mathrm{CO}_{2}$ supply price for all projects in our sample and the corresponding amount of $\mathrm{CO}_{2}$ stored. The $\mathrm{CO}_{2}$ supply price is taken as negative if acquiring $\mathrm{CO}_{2}$ represents a cost for the $\mathrm{CO}_{2}$-EOR project (as in current practice) and positive if the EOR operator receives revenue from providing storage services (the desired practice). As noted earlier, we do not explicitly take into account supply-side economics such as the $\mathrm{CO}_{2}$ emission price or the cost of capture and transportation, as we assume these will be factored into the final $\mathrm{CO}_{2}$ supply price for the EOR operator. For example, assuming a cost of $\$ 50 / \mathrm{tCO}_{2}$ for capture and transport, a $\$ 10 / \mathrm{tCO}_{2}$ supply price would be consistent with an emissions value of $\$ 60 / \mathrm{tCO}_{2}$.

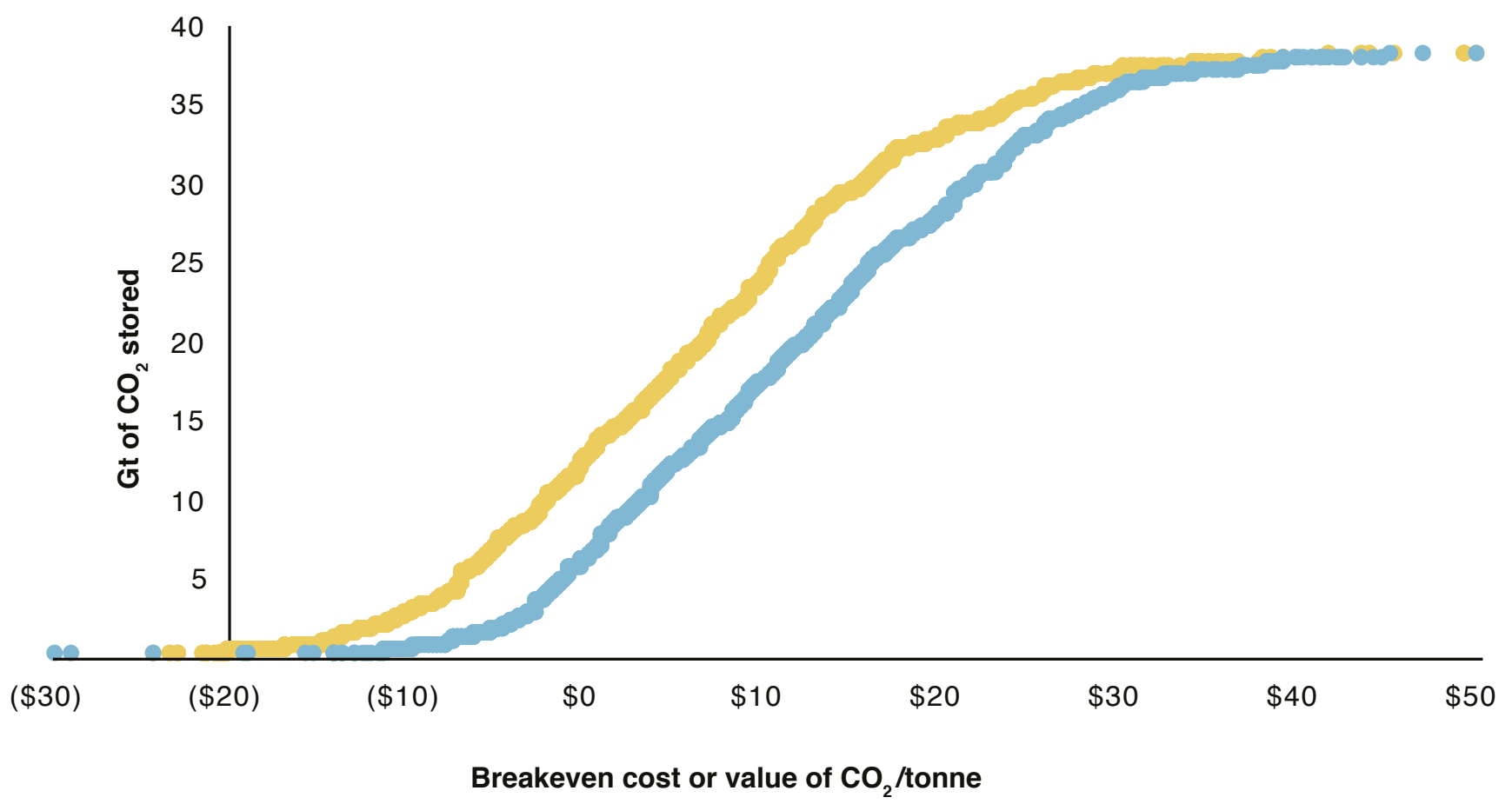

Pre-tax/royalty NPV

Post-tax/royalty NPV

Figure 6. Impact of tax and royalty on NPV break-even value for $\mathrm{CO}_{2} @ \$ 50 / \mathrm{bbl}$.

Source: KAPSARC. 
The plots in Figure 6 show the amount of $\mathrm{CO}_{2}$ that is stored for varying break-even $\mathrm{CO}_{2}$ prices and for a fixed oil price of $\$ 50 / \mathrm{bbl}$. Since petroleum taxation is known to have a significant effect on the profitability of EOR projects, we plotted the curves both for the pre- and post-tax situations using country-specific tax rates collected from the IHS Markit Vantage system. Comparing the two curves quantifies the extent to which petroleum taxes and charges affect the economics of storage-focused $\mathrm{CO}_{2}$-EOR projects. The median of $\mathrm{CO}_{2}$ break-even value in our model is about $\$ 6 / \mathrm{tCO}$ of revenue received by the operator pre-tax and increases to about \$12/ $\mathrm{tCO}_{2}$ post-tax, showing that petroleum taxes and charges have the potential to significantly erode the financial feasibility of these projects. The shape of the curve, with an almost linear middle section from $\$ 0 / \mathrm{tCO}_{2}$ to $20 / \mathrm{tCO}_{2}$, indicates that the supply price is a significant factor driving the total storage of $\mathrm{CO}_{2}$. Within this price range, for projects seeking to optimize oil production and storage, each dollar of additional revenue could prompt an additional 1 billion $\mathrm{tCO}_{2}$ stored outside of North America. Beyond
$\$ 20 / \mathrm{tCO}_{2}$, the technical costs become much higher and the pool of economically viable projects begins to shrink.

The results presented so far, linked to a fixed oil price assumption of $\$ 50 / \mathrm{bbl}$, show approximately $6.1 \mathrm{GtCO}_{2}$ of economic storage potential under commercial schemes in which the operator receives no revenue from storage (i.e., without the need for any additional subsidies). In contrast to the strictly technical potential highlighted earlier, an economic analysis shows the largest potentials to be in China, Russia, Indonesia, Oman and Iran. Additionally, it becomes clear that several of the largest projects could pay for $\mathrm{CO}_{2}$ to enhance oil production as their break-even prices are negative (Table 1).

Testing the sensitivity of break-even $\mathrm{CO}_{2}$ prices to changes in the oil price has a predictable result, with higher oil prices driving lower break-evens (Figure 7). Clearly, this indicates that under higher oil prices, producers find more value in injecting $\mathrm{CO}_{2}$ and will do so even if they are paid less for $\mathrm{CO}_{2}$ storage.

Table 1. Large $\mathrm{CO}_{2}$-EOR projects with negative post-tax $\mathrm{CO}_{2}$ break-even supply prices.

\begin{tabular}{l|l|l|l} 
Country & Project & Post-tax break-even $\left(\$ \mathbf{t} \mathbf{C O}_{2}\right)$ & $\mathbf{C O}_{2}$ stored $(\mathbf{M t})$ \\
\hline China & Jiangsu & $(2.75)$ & 275 \\
\hline China & Henan & $(2.74)$ & 250 \\
\hline Oman & Lekhwair & $(7.77)$ & 187 \\
\hline Russia & Arlanskoye & $(0.29)$ & 141 \\
\hline Indonesia & Rantau & $(1.92)$ & 135 \\
\hline Russia & Chutyrsko-Kiyengoskoye & $(1.45)$ & 118 \\
\hline Oman & Al Huwaisah & $(1.11)$ & 115 \\
\hline Russia & Igrovkoye & $(0.94)$ & 108 \\
\hline Iran & Naft-I-Shahr & $(10.15)$ & 101
\end{tabular}

Source: KAPSARC. 


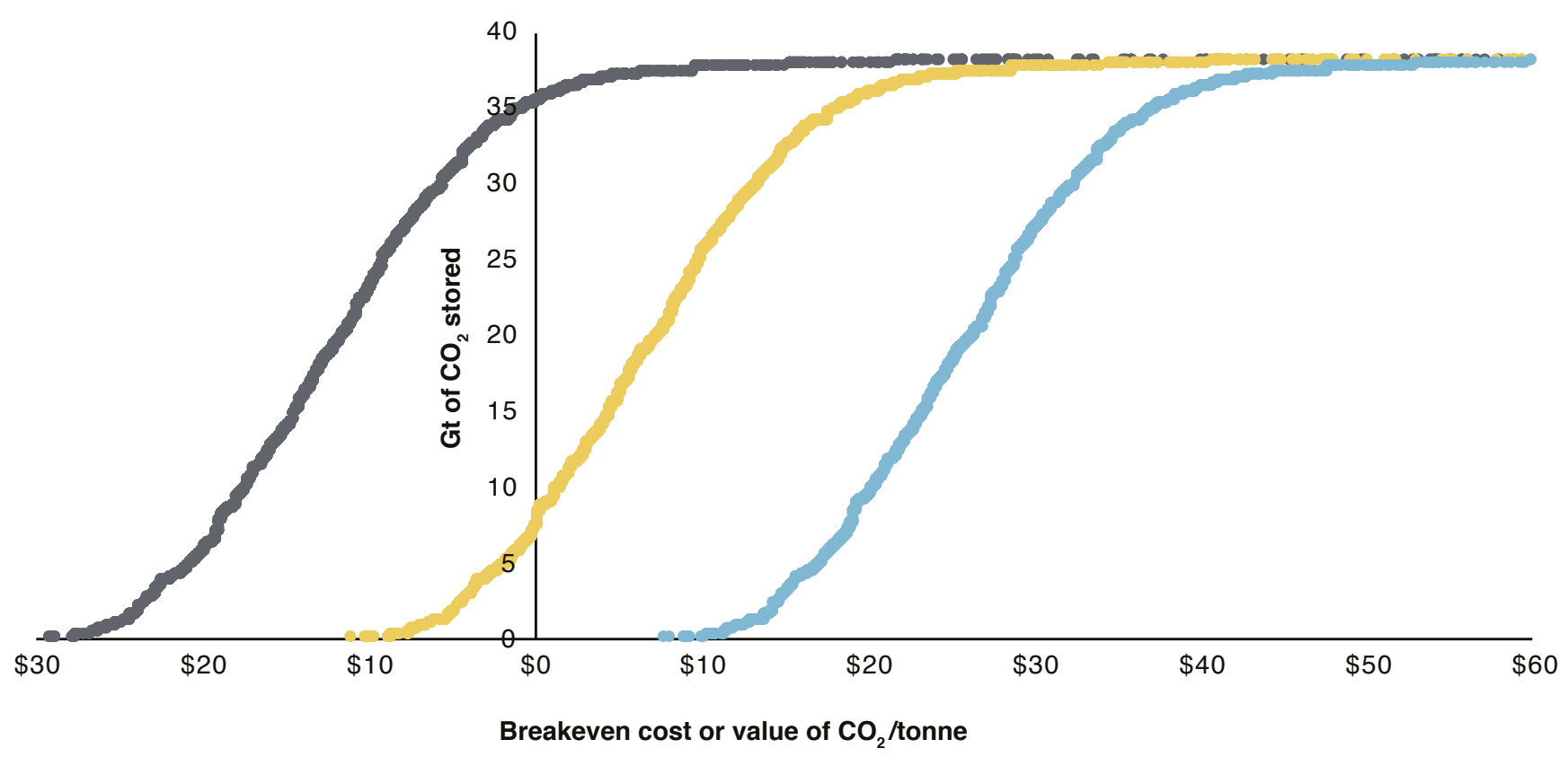

$\$ 70 / \mathrm{bbl} \quad \$ 50 / \mathrm{bbl} \quad \$ 30 / \mathrm{bbl}$

Figure 7. Effect of oil price on storage potential and $\mathrm{CO} 2$ break-even prices.

Source: KAPSARC.

Figure 7 demonstrates that changes in the oil price have a net effect of shifting the entire storage curve. The shape of the curve remains unchanged, indicating that the behavior of the $\mathrm{CO}_{2}$ supply price is relatively stable assuming a fixed injection rate. More interesting is the finding that most of the change in storage potential occurs only over a small range of $\mathrm{CO}_{2}$ supply prices $(\sim 20)$. This indicates that the general engineering and financial hurdles of these projects, while varied, have similar outcomes. The steep and linear slope implies that setting the $\mathrm{CO}_{2}$ supply price at an appropriate level could act as a lever for increasing storage.

It is notable that the horizontal shift in the curves is almost $\$ 1$ of $\mathrm{CO}_{2}$ price substituting $\$ 1$ of oil price. This is because the CAPEX and OPEX are fixed with only the oil and $\mathrm{CO}_{2}$ cash flows as variable. When the oil price drops, the $\mathrm{CO}_{2}$ cash flow must rise to offset the lost revenue and maintain the breakeven point. The $\mathrm{CO}_{2}$ consumption is a fixed ratio of $0.6 \mathrm{tCO}_{2}$ per barrel, and the aggregate discount rates for oil and $\mathrm{CO}_{2}$ are 36 percent and 54 percent, respectively (see Appendix A). Multiplying these values $\left(\$ / \mathrm{bbl}^{*} 1 \mathrm{bbl}{ }^{*} 36\right.$ percent $=0.36, \$ /$ tonne ${ }^{*} 0.6 \mathrm{tCO}_{2}{ }^{*} 54$ percent $=0.34$ ) yields a ratio of 93 percent of the oil price movement to the $\mathrm{CO}_{2}$ price offset.

As mentioned earlier, oil producers' application of $\mathrm{CO}_{2}$ injection may vary significantly depending on the positive or negative price of the $\mathrm{CO}_{2}$ supply available to them. If the $\mathrm{CO}_{2}$ was an expense instead of a revenue, the operators would likely revert to the traditional injection rate of $0.3 \mathrm{tCO}_{2} /$ bbl to reduce costs. At the lower injection rate, the incremental recovery is also half the factor for storage-focused EOR (6.5 percent of OOIP instead of 13 percent) which implies:

The number of $\mathrm{CO}_{2}$-EOR projects increases, as they are not ruled out for having insufficient supply. 
When $\mathrm{CO}_{2}$-supply prices are negative, the operator incurs lower costs and more projects are profitable.

Essentially, the real-world behavior of an operator changes at the point where the $\mathrm{CO}_{2}$ supply price switches from positive to negative. Under negative $\mathrm{CO}_{2}$ supply prices, more $\mathrm{CO}_{2}$ is profitably stored through conventional $\mathrm{CO}_{2}$-EOR practices than through storage-focused $\mathrm{CO}_{2}$-EOR (Figure 8). For positive prices, the additional revenues from storagefocused projects raises the total $\mathrm{CO}_{2}$ sequestered.

\section{The impact of relaxing supply constraints}

Applying the methodology described above, in which $\mathrm{CO}_{2}$ supply is constrained in various ways, yields a total economically viable $\mathrm{CO}_{2}$-EOR storage capacity of $40 \mathrm{GtCO}_{2}$. This is significantly less than the technical potential for global storage capacity (including North America) of $240 \mathrm{GtCO}_{2}$, as estimated by the IEA, for storage-focused $\mathrm{CO}_{2}$-EOR (IEA 2015).

With this consideration in mind, we extended our analysis to remove the constraint of $\mathrm{CO}_{2}$ supply limitations such that project profitability becomes the determining factor for viability. Using the methodology described above to calculate $\mathrm{CO}_{2}$ supply prices against potential storage, we find a total technical potential for onshore storage capacity of $190 \mathrm{GtCO}_{2}$, almost fivefold more than the previously calculated economic storage potential of $40 \mathrm{GtCO}_{2}$ (Figure 9). This changes the curve in relation to $\mathrm{CO}_{2}$ supply price increases: in contrast to the smooth initial curve, the new curve appears jagged due to the inclusion of a few very large fields that have outsized impacts on the results. The vertical portion to the right is a cluster of very big fields in Saudi Arabia, for instance. The figure also shows that taxation appears to have a smaller impact at this scale, due to the larger volume of projects in the sample.

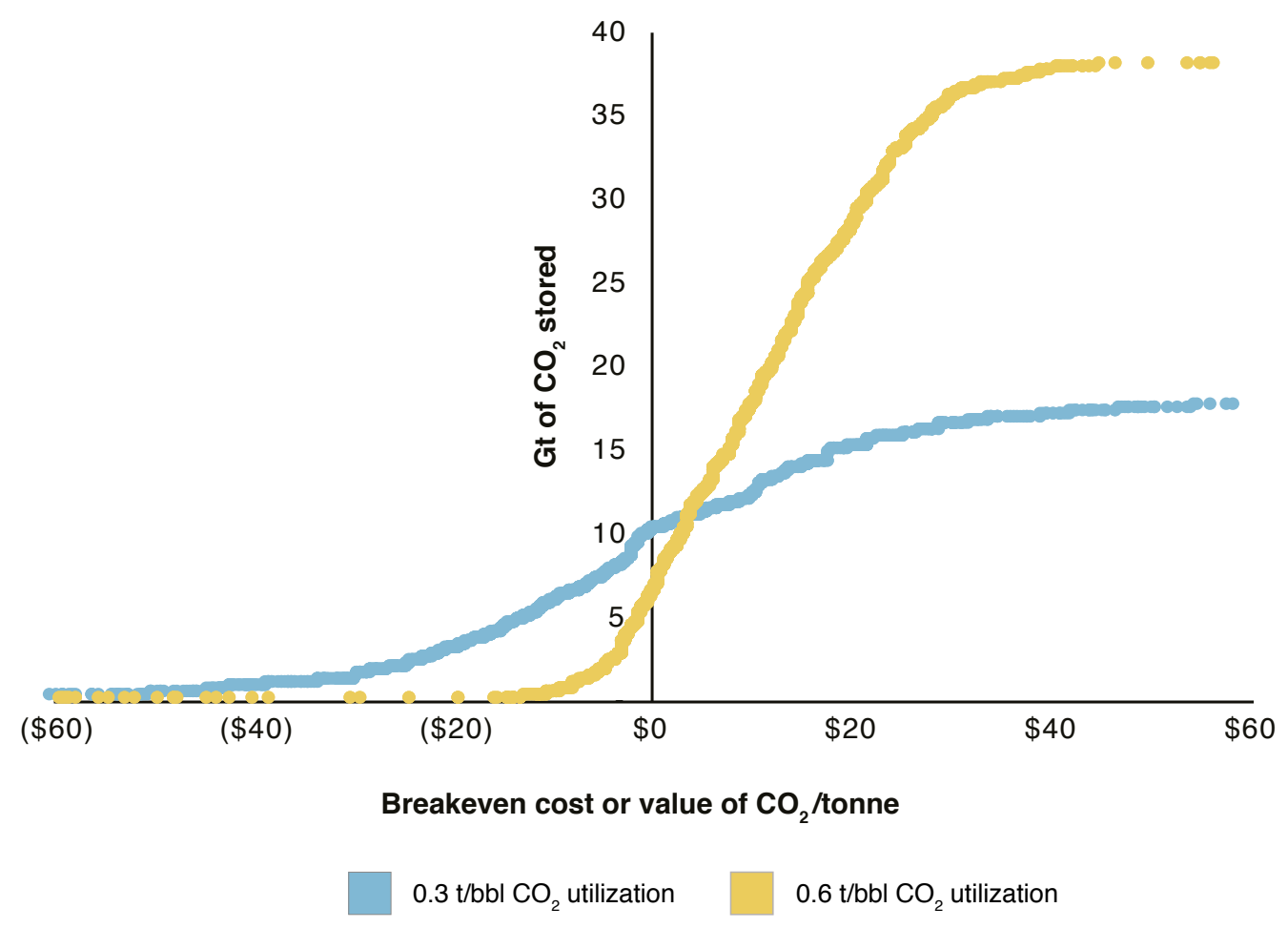

Figure 8. Effect of $\mathrm{CO}_{2}$ utilization factor on economic storage potential @ \$50/bbl.

Note: EOR refers to $0.3 \mathrm{t} / \mathrm{bbl} \mathrm{CO}{ }_{2}$ injection rates. EOR+ is $0.6 \mathrm{t} / \mathrm{bbl} \mathrm{CO}_{2}$ injection, leading to more storage.

Source: KAPSARC. 


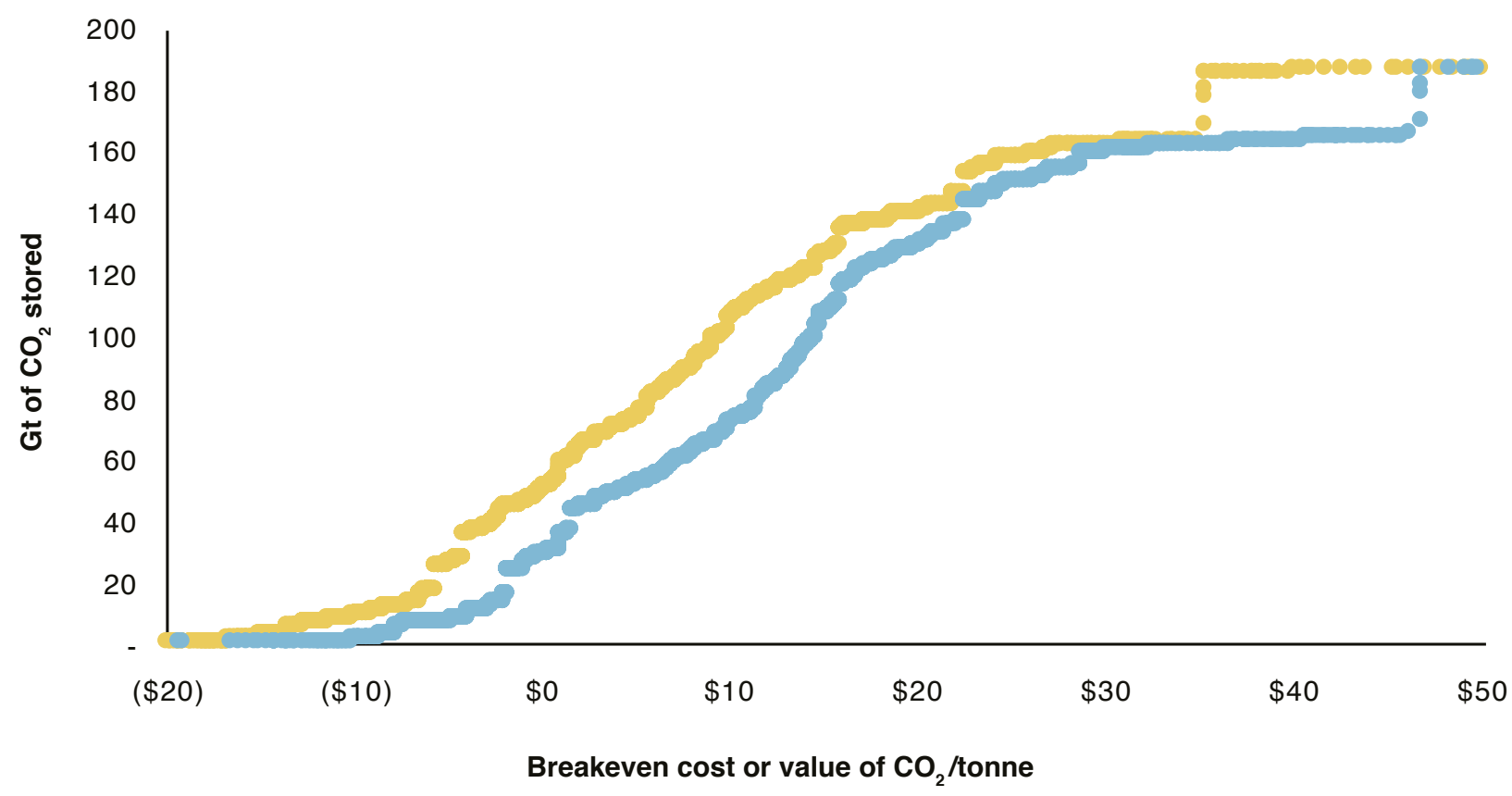

Pre-tax

Post-tax

Figure 9. Pre- versus post-tax unconstrained break-even $\mathrm{CO}_{2}$ values @ \$50/bbl.

Source: KAPSARC.

Under this extended analysis, the range of prices that affect storage potential is very similar to the first results (Figure 6); the median supply price is still somewhere around the $\$ 15 / \mathrm{tCO}_{2}$ paid to the operator for storage. The difference is that total storage is much bigger.

Examining data for Saudi Arabia highlights the difference between technical and economic potential. Under the methodology that includes the initial constraints, the economic storage potential of Saudi Arabia is estimated as 788 million tonnes of $\mathrm{CO}_{2}\left(\mathrm{MtCO}_{2}\right)$, which is less than one-tenth of the economic storage potential of Russia $\left(9.925 \mathrm{GtCO}_{2}\right)$. As noted, this estimate is predicated on several assumptions, the most important of which are:

$\mathrm{CO}_{2}$ demand assumes that the entire field is developed at once.
$\mathrm{CO}_{2}$ supply from a single source is sufficient to meet the maximum volume of $\mathrm{CO}_{2}$ demanded by the EOR project.

The distance of a pipeline (or network of pipelines) is constrained to less than $500 \mathrm{~km}$.

Emission sources are fixed and do not change with future developments.

In reality, the storage potential in some Saudi fields is so vast that supplying sufficient $\mathrm{CO}_{2}$ for a full EOR project from a single source is practically impossible. A realistic implementation of $\mathrm{CO}_{2}$-EOR in such situations would be phased, with small sections of the field developed sequentially as the $\mathrm{CO}_{2}$ supply can support it. Without these limiting criteria, the total possible storage of Saudi Arabia climbs to $25 \mathrm{Gt}$, more than half of the total in our primary analysis. 
Globally, a phased construction approach for larger projects could expand the $\mathrm{CO}_{2}$ supply. Where this approach is not possible or economically viable, an alternative could be front-loading with aquifer storage. $\mathrm{A} \mathrm{CO}_{2}$ producer lacking sufficient supply to cover the maximum demand of an EOR project could pre-charge an aquifer to support the initial phases of the WAG injection, when huge volumes of $\mathrm{CO}_{2}$ are needed. Large pipeline networks to collect and distribute $\mathrm{CO}_{2}$ among multiple sources and sinks may also help address constraints caused by $\mathrm{CO}_{2}$ shortages.
As estimates in this analysis are made on current conditions and $\mathrm{CO}_{2}$ emissions data, it should be noted that some key assumptions may change in the future. With rising $\mathrm{CO}_{2}$ demand from EOR fields it may become advantageous to locate emissions sources close to potential storage sites. In addition, in the largest fields, economies of scale can make supply options such as a longer pipeline, or a network connecting multiple sources economically advantageous. Such developments would substantially change the results of the present analysis. 


\section{Conclusion}

W

ith a specific focus on regions outside North America, we examined the economic potential to apply $\mathrm{CO}_{2}$-EOR technologies to $\mathrm{CO}_{2}$ storage, and the relationship between the supply price of $\mathrm{CO}_{2}$ and the storage capacity in oil fields. Our analysis shows that storage-focused $\mathrm{CO}_{2}$-EOR projects outside of North America have the potential to store up to 40 $\mathrm{GtCO}_{2}$ from existing large-scale stationary sources. In some regions, storage potential vastly exceeds currently available $\mathrm{CO}_{2}$ supply from such sources.

The amount of $\mathrm{CO}_{2}$ stored depends on the profitability of $\mathrm{CO}_{2}$-EOR, which in turn is influenced by the value of $\mathrm{CO}_{2}$ to an EOR operator. Two key elements can change the value equation substantially:

When the price of oil increases, the value of $\mathrm{CO}_{2}$ as an input to enhance production increases.

Alternatively, implementation of a carbon pricing policy by governments creates value for $\mathrm{CO}_{2}$ storage.

Regardless of whether governments create the latter value through subsidies, tax credits, emissions trading or tax on the emitters, concrete financial benefits arise from encouraging additional $\mathrm{CO}_{2}$ storage in oil fields.

For the $\mathrm{CO}_{2}$ injection rates assumed in the analysis, we find that independent of the oil price, even moderate changes in $\mathrm{CO}_{2}$ supply prices can significantly affect the economics of $\mathrm{CO}_{2}$ storage. For an oil price of $\$ 50 / \mathrm{bbl}$ and a $\mathrm{CO}_{2}$ supply price in the range $\$ 10 / \mathrm{tCO}_{2}$ to $\$ 15 / \mathrm{tCO}_{2}$, with $\mathrm{CO}_{2}$ supply constraints taken into account, we find at the aggregate level an economically viable storage capacity of $20 \mathrm{GtCO}_{2}$. Without these supply constraints, accessible storage space increases as much as fivefold at these pricing levels.

Our study delivers three key policy-relevant insights. First, it suggests an optimal range of $\mathrm{CO}_{2}$ supply prices to encourage an increase in the storage component of $\mathrm{CO}_{2}$-EOR projects. For a given oil price, the range over which the $\mathrm{CO}_{2}$ supply price can affect storage potential is quite narrowly defined in the interval of $\$ 10$ to $\$ 30 / \mathrm{tCO}_{2}$ for an oil price of $\$ 50 / \mathrm{tCO}_{2}$.

Second, we show that petroleum taxation has a detrimental effect on the availability of economic storage by lowering the profitability of individual projects. The policy implication is that oil producing countries seeking to implement $\mathrm{CO}_{2}$-focused storage projects may wish to revisit their petroleum fiscal regimes to avoid negative interaction with $\mathrm{CO}_{2}$ storage policies.

Third, our results show that economically viable storage is limited by current $\mathrm{CO}_{2}$ supply. Large $\mathrm{CO}_{2}$ transportation infrastructure could unlock additional $\mathrm{CO}_{2}$-EOR storage opportunities and allow for oil producers to engage in decarbonization on a meaningful scale. 


\section{References}

ARI, 2010. “U.S. Oil Production Potential from Accelerated Deployment of Carbon Capture and Storage." Advanced Resources International Inc. Arlington, Virginia.

Dai, Zhenxue, Richard Middleton, Hari Viswanathan, Julianna Fessenden-Rahn, Jacob Bauman, Rajresh Pawar, Si-Yong Lee and Brian McPherson." An Integrated Framework for Optimizing $\mathrm{CO}_{2}$ Sequestration and Enhanced Oil Recovery." Environmental Science and Technology Letters 1 (2014):49-54

EDGAR. "Emissions Database for Global Atmospheric Research.” Last accessed Sept. 25, 2016: http://edgar.jrc. ec.europa.eu/

Godec, Michael, Vello A. Kuuskraa, and Phil Dipietro. "Opportunities for using anthropogenic $\mathrm{CO}_{2}$ for enhanced oil recovery and $\mathrm{CO}_{2}$ storage." Energy Fuels 27 (2013): 4183-4189.

IEA 2015. "Storing $\mathrm{CO}_{2}$ through Enhanced Oil Recovery." International Energy Agency, Paris.

IEA 2016. "Energy Technology Perspectives 2017." International Energy Agency, Paris.

IEAGHG 2009. " $\mathrm{CO}_{2}$ Storage in Depleted Oilfields: Global Application Criteria for Carbon Dioxide Enhanced Oil Recovery." IEA Greenhouse Gas R\&D Programme, Cheltenham. www.ieaghg.org/docs/General Docs/ Reports/2009-12.pdf

IEAGHG 2016. "Emissions accounting for $\mathrm{CO}_{2}$-EOR" IEA Greenhouse Gas R\&D Programme, Cheltenham.
IHS Markit Vantage Database. Last accessed October 2017: http://vantage.ihsenergy.com/

IHS Markit QUE\$TOR Cost Estimation Tool. Last accessed October 2017: https://ihsmarkit.com/products/ questor-oil-gas-project-cost-estimation-software.html

Kovscek, A.R. and M.D. Cakici 2015. "Geologic storage of carbon dioxide and enhanced oil recovery II. Cooptimization of storage and recovery." Energy Conversion \& Management 46:1941-1956.

Leach, Andrew, Charles F. Mason, and Klaas van't Veld 2011. "Co-optimisation of enhanced oil recovery and carbon sequestration." Resource and Energy Economics 33:893-912.

Jarrel, Perry M., Charles E. Fox, Michael H. Stein and Steven L. Webb 2002." Practical Aspects of $\mathrm{CO}_{2}$ Flooding." SPE Monograph Series, vol. 22.

NETL 2011. "Improving Domestic Energy Security and Lowering $\mathrm{CO}_{2}$ Emissions with "Next Generation" $\mathrm{CO}_{2}-$ Enhanced Oil Recovery ( $\mathrm{CO}_{2}$-EOR)." National Energy Technology Laboratory and Ü.S. Department of Energy (2011).

NETL 2014. "Acquisition and Development of Selected Cost Data for Saline and Enhanced Oil Recovery (EOR) Operations." National Energy Technology Laboratory and U.S. Department of Energy.

Saini, Dayanand 2015. " $\mathrm{CO}_{2}$-Prophet model based evaluation of $\mathrm{CO}_{2}$-EOR and storage potential in mature oil reservoirs." Journal of Petroleum Science and Engineering 134: 79-86. 


\section{Appendix A: Cost Analysis}

$\mathrm{T}$ The economic analysis carried out for this report takes into account the main cost elements and sources of revenue for a typical $\mathrm{CO}_{2}$-EOR operation, based on a simplified representation of oil production and $\mathrm{CO}_{2}$ injection profiles.

\section{Injection and production profiles}

With a sole focus on estimating $\mathrm{CO}_{2}$-EOR project profitability, we use a simplified approach that relies on a set of dimensionless oil production and $\mathrm{CO}_{2}$ injection curves (Figure A1). These curves relate incremental oil production (expressed as a fraction of

maximum production) to the percentage of injectants required to fill the hydrocarbon pore volume (HCPV).

These curves were generated using the $\mathrm{CO}_{2}$ -

Prophet model, a $\mathrm{CO}_{2}$-EOR estimation software developed by Texaco for the U.S. Department of Energy (Saini, 2006), and reflect a $\mathrm{CO}_{2}-$ EOR project in which pure $\mathrm{CO}_{2}$ is injected (filling 10 percent of the HCPV) followed by a WAG phase implementing a $\mathrm{CO}_{2}$-to-water ratio of $1: 1$. The curves capture the main characteristics of a $\mathrm{CO}_{2}$-EOR flood, including the absence of a production plateau and a steep production decline. In reality, individual projects may show considerable variation from the performance characteristics assumed in this calculation.

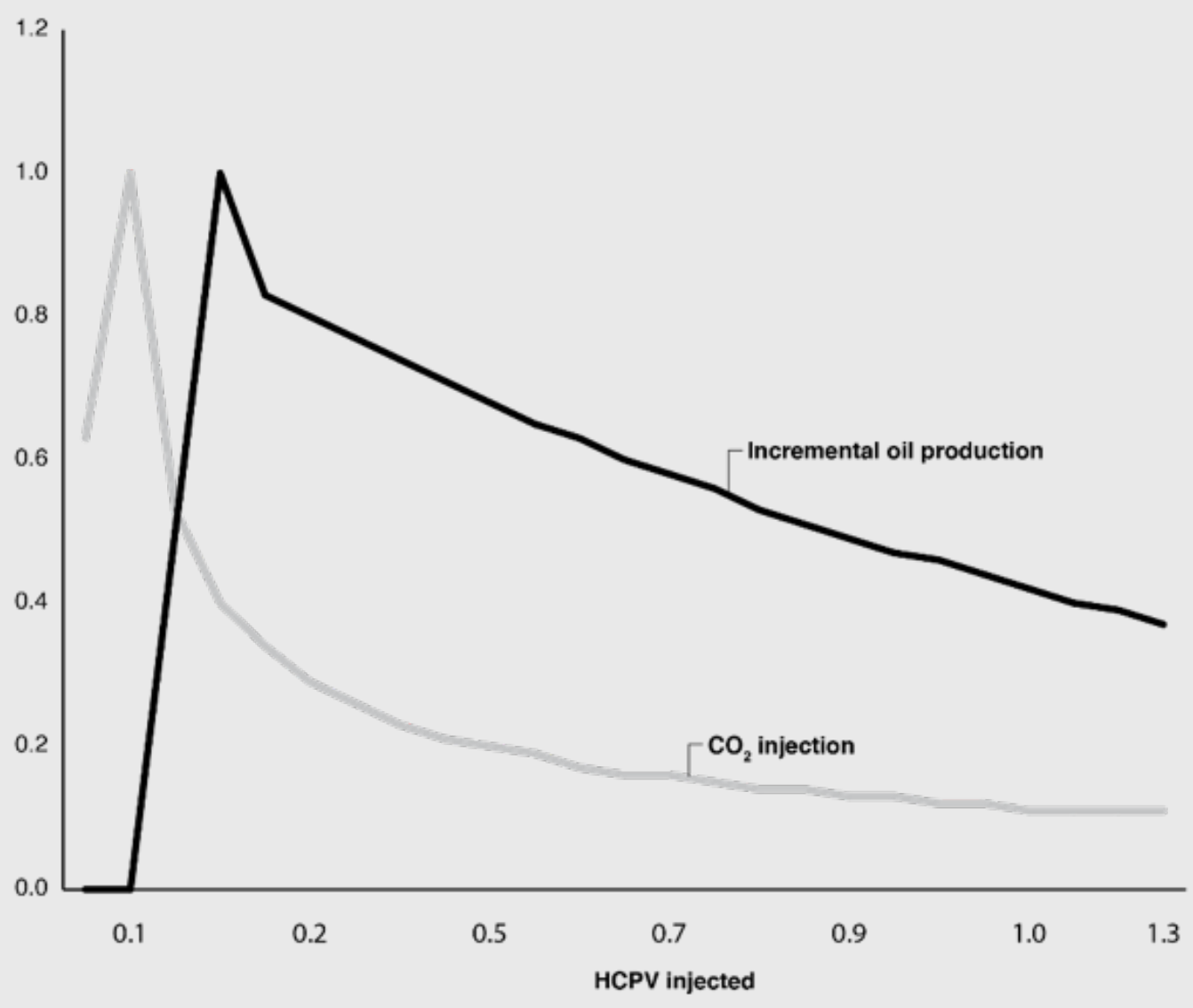

Figure A1. Variation of incremental oil production and $\mathrm{CO}_{2}$ demand with injected HCPV.

Note: Oil production and $\mathrm{CO}_{2}$ demand are quantified as fractions of their corresponding maximum values.

Source: KAPSARC. 
The usefulness of the figures is that they can be scaled to fit larger or smaller developments. For example, we may apply a 10 percent NPV to these values, and determine the present value of future revenues (or potential costs in the case of $\mathrm{CO}_{2}$ ) in relation to the total volumes. In this case, the $\mathrm{CO}_{2}$ NPV is 54 percent of the total value, while oil NPV is 36 percent. This is due to the majority of $\mathrm{CO}_{2}$ use occurring early in the project, with a sharp reduction afterward. Oil production occurs after an initial delay and declines at a gentle rate, leading to a larger reduction of the total value once NPV has been applied.

\section{Production and injection wells}

\section{Number of wells}

EOR wells are much less productive than regular wells, and as such many more are required than in a normal upstream development. This means that production is much more localized, with a nearby injector 'pushing' oil toward a producer. In a normal upstream project, a net productivity of $8 \mathrm{MMbbl}$ per well is normal; for EOR projects, a value closer to 600,000 barrels is more usual.

First, we solve for the number of existing producers and injectors of the upstream project. Multiplying the OOIP by the ultimate recovery factor (the percentage of recoverable reserves) determines the total volume of oil that would have been produced without EOR. This value is then divided by the typical $8 \mathrm{MMbbl}$ per producer. Based on analyzed projects, existing injection wells are equal to about 40 percent of the existing producers.

OOIP * Ultimate recovery $\%=$ Primary and secondary production $\frac{\text { Primary and secondary production }}{8 \text { million barrels productivity }}=$ Existing production wells
Existing production wells $* 40 \%=$ Existing injection wells
We now solve for the number of new producers and injectors. Rystad provides data on the incremental oil from the reservoir; we merely divide this value by the expected productivity of 600,000 barrels. Note that this calculation is for the total number of producers, as existing wells will also benefit from the EOR process. The number of new producers is the difference between the total wells and the existing ones.

\footnotetext{
$\frac{\text { Incremental oil production }}{600,000 \text { barrels productivity }}=$ Total production wells

Total production wells - Existing production wells $=$ New production wells
}

Due to the use of drilling patterns, the total number of injection wells in an EOR project matches the total number of production wells. Typically, four injection wells surround a single producer, driving the oil toward the middle (Figure A2), with this pattern repeated in a giant grid over the reservoir. Across a large enough pattern, the number of injectors and producers is ultimately the same.

Carrying on, we solve the number of new injectors as follows:

Total production wells $=$ Total injection wells

Total injection wells - Existing injection wells $=$ New injection wells

\section{Surface costs}

For each well, whether existing or new, new surface equipment will need to be installed, ranging from a collection of valves and/or regulators to the wellhead itself. As $\mathrm{CO}_{2}$ is a highly corrosive substance, this equipment must be upgraded or replaced even on existing wells. Based on some sample projects built in IHS QUE\$TOR, the cost of new equipment was determined to be approximately $\$ 200 \mathrm{k} /$ producer and $\$ 250 \mathrm{k} /$ injector. 


\section{Cost per well}

Depending on reservoir characteristics, the cost of a single well can vary widely. Reservoir depth is the major determinant. We derived an equation to solve for the cost per foot of drilling, completion and rework by running multiple QUE\$TOR examples (the equation itself cannot be shared due to intellectual property rights).

\section{$\mathrm{CO}_{2}$ recycle system (separator and compressors)}

In line with the Kinder Morgan model used as a guide for this analysis, the separators and compressors that comprise the recycle system are priced together.
However, as the original cost was quoted in 2000, we applied the IHS Capital Cost Index (used to track change in costs over time for upstream developments) to estimate current values. The original cost, quoted as a function of system capacity and using million standard cubic feet (MMscf), was approximately $\$ 1,200 / \mathrm{MMscf} /$ year; it revises to a current cost of about $\$ 2,170 / \mathrm{MMscf} /$ year.

\section{Operations cost}

As proposed in NETL (2014), we assume that the OPEX (expressed in \$/Mcf [thousand cubic feet]) for projects analyzed is set at 1 percent of the oil price per barrel; ergo, for an oil price of $\$ 50 / \mathrm{bbl}$, OPEX is $\$ 0.50 /$ Mcf.

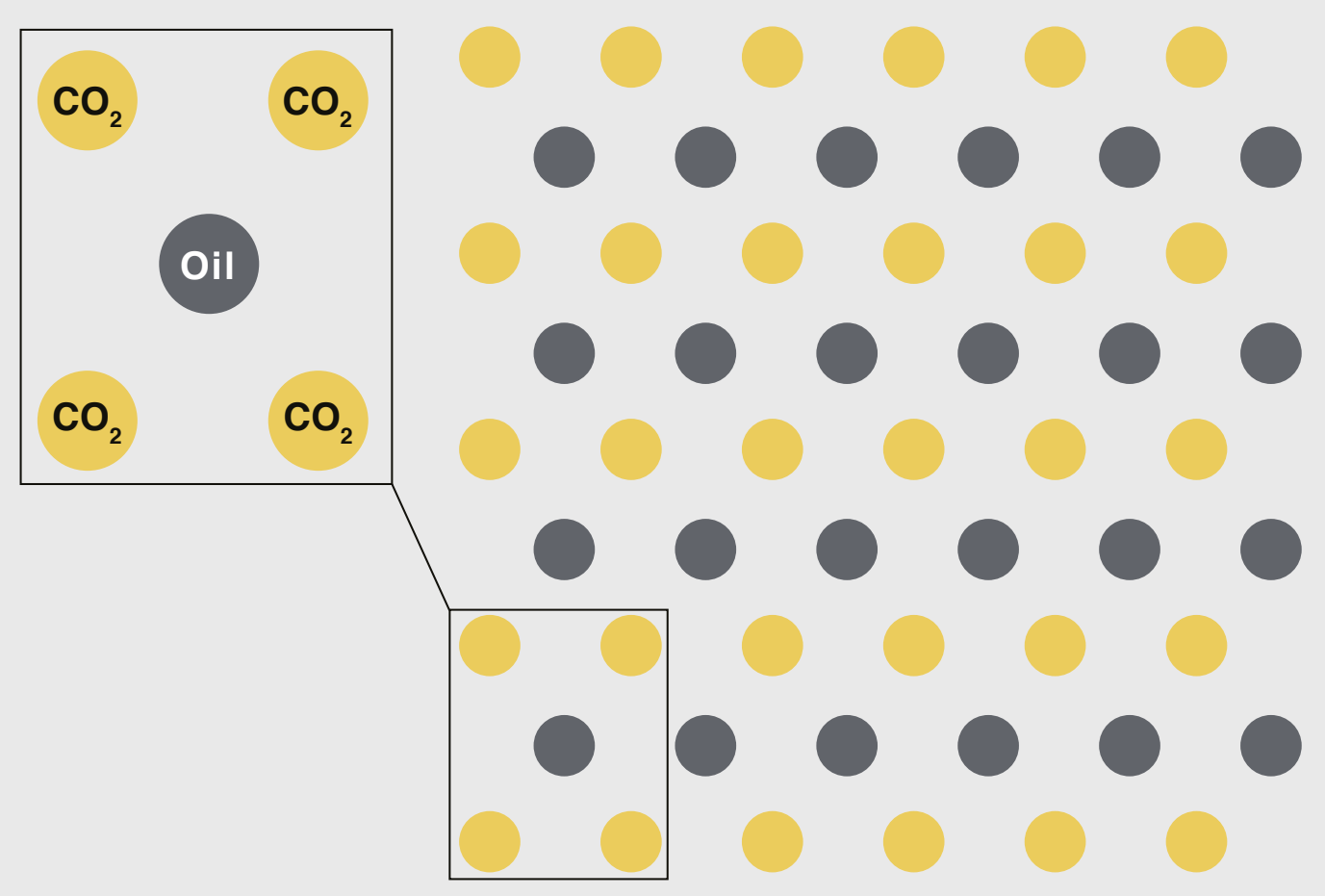

Figure A2. A Five-spot EOR well pattern.

Source: KAPSARC. 


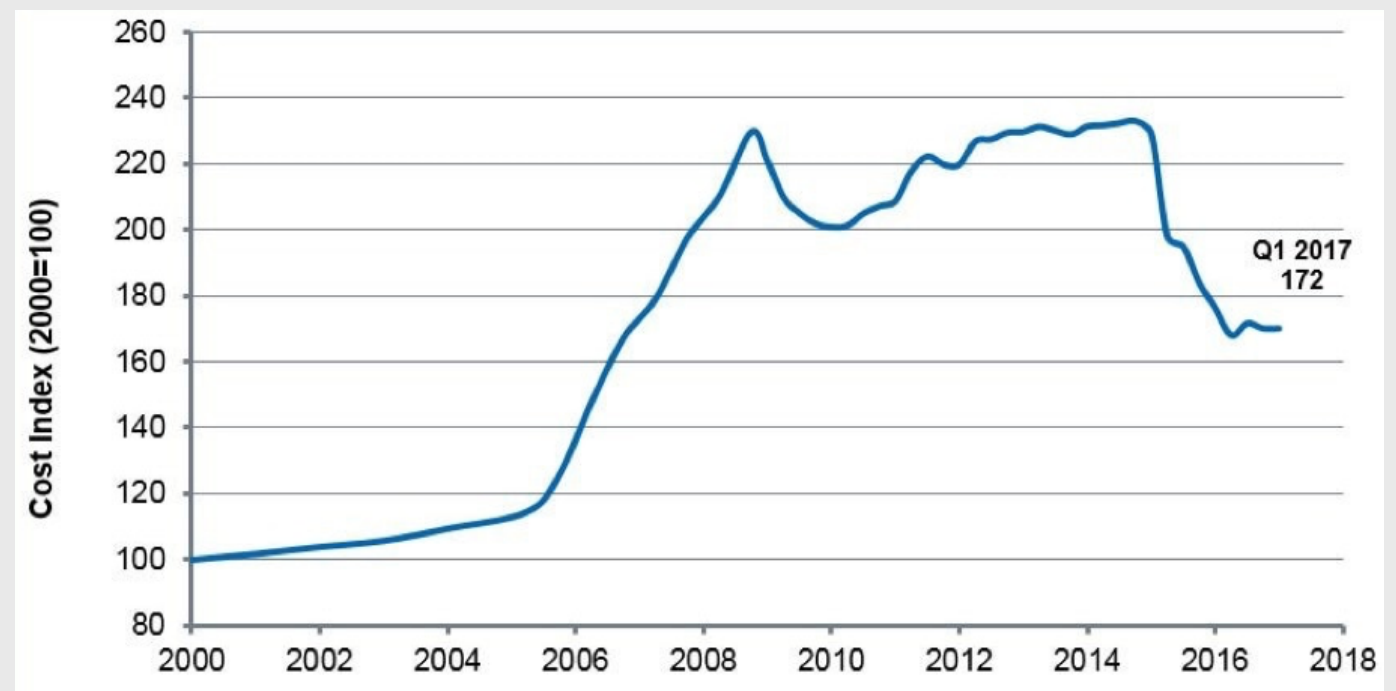

Figure A3. IHS Markit upstream capital cost index, used to update recycle system costs.

Source: IHS Markit.

\section{Decommissioning}

Using benchmarks generated from QUE\$TOR, we estimated the DECOM cost by examining various portions of each project. We based our calculations on the extra costs associated with $\mathrm{CO}_{2}$-EOR only, as existing elements (such as wells) should be accounted for in the decommissioning of the original project. As such, the recycle system was treated as a new facility/equipment and the decommissioning costs were estimated to be about 27 percent of CAPEX. Costs to decommission new wells are much lower, with only 6 percent of CAPEX allocated. 


\section{About the Authors}

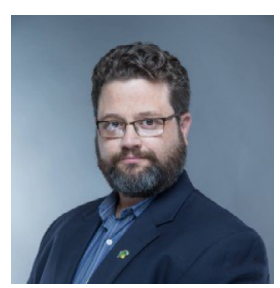

\section{Colin Ward}

Colin is a research fellow in KAPSARC's Markets and Industrial Development program. He has worked in the energy industry for 10 years in various capacities including seismic field work, refinery design and consulting for major international and national oil companies worldwide. Colin plays a major role in several KAPSARC projects, primarily focusing on cost estimation for energy projects and environmental impacts of the global energy industry. He holds an MBA (University of Texas), B.S. Electrical Engineering (University of Houston), and a B.A. Philosophy (Tulane University).

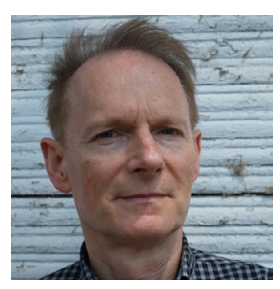

\section{Wolfgang Heidug}

Wolfgang is an expert on low-carbon energy technology policy with in-depth knowledge of the science and technology of $\mathrm{CO}_{2}$ capture and storage. Prior to joining KAPSARC he was a senior adviser at the International Energy Agency in Paris. Wolfgang has over 20 years' experience working with Shell International. He obtained his Ph.D. in Engineering from the U.S. and holds a M.S. in Physics and Economics from Germany.

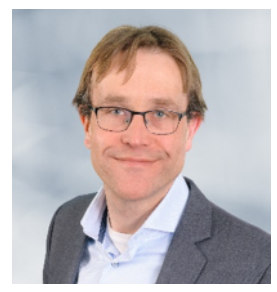

\section{Nils-Henrik Bjurstrøm}

Nils-Henrik is a product portfolio manager at Rystad Energy with overall responsibility for the management of its commercial products. He was a senior project manager within Rystad Energy consulting for three years. Nils-Henrik previously worked at Roxar Software Solutions as a manager and developer of software products within petroleum geology, geophysics and reservoir engineering. He holds an M.S. in Applied Mathematics from the Norwegian University of Technology and Science and an Executive MBA in Strategic Management from the Norwegian School of Economics.

\section{About the Project}

Pathways to Low Carbon Oil is a project that will examine the global challenges and opportunities for oil in a carbon constrained world. With a focus on Saudi Arabia's competitiveness in this emerging market, we examine the existing carbon intensity of upstream operations and the opportunities to reduce that intensity through management strategies and technology, as well as the economic impacts. Understanding the market and player behaviors will provide insights to policy options along with the legal, regulatory and commercial issues that must be addressed. 
INAPSARC

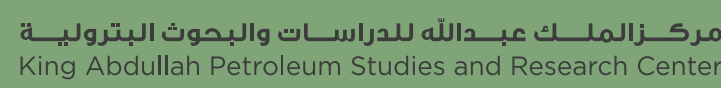

www.kapsarc.org 